\title{
p42/p44 MAPK-mediated
}

\section{Stat3Ser727 phosphorylation is \\ required for progestin-induced \\ full activation of Stat3 and breast cancer growth}

\author{
Mercedes Tkach, Cinthia Rosemblit, Martín A Rivas*, Cecilia J Proietti, \\ María Celeste Díaz Flaqué, María Florencia Mercogliano, Wendy Beguelin, \\ Esteban Maronna', Pablo Guzmán², Felipe G Gercovich ${ }^{3}$, Ernesto Gil Deza ${ }^{3}$, \\ Patricia V Elizalde and Roxana Schillaci
}

\author{
Laboratory of Molecular Mechanisms of Carcinogenesis, Instituto de Biología y Medicina Experimental, CONICET, \\ Vuelta de Obligado 2490, Buenos Aires C1428ADN, Argentina \\ ${ }^{1}$ Servicio de Patología, Sanatorio Mater Dei, San Martín de Tours 2952, 1425 Buenos Aires, Argentina \\ 2Departamento de Anatomía Patológica (BIOREN), Facultad de Medicina, Universidad de La Frontera, Manuel \\ Montt 112, 4781176 Temuco, Chile \\ ${ }^{3}$ Instituto Oncológico Henry Moore, Agüero 1245, 1425 Buenos Aires, Argentina \\ ${ }^{*} M$ A Rivas is now at Experimental Therapeutics Laboratory, Vall d'Hebron Institute of Oncology, Passeig Vall \\ d'Hebron 119-129, 08035 Barcelona, Spain
}

Correspondence should be addressed to $\mathrm{R}$ Schillaci Email

rschillaci@

ibyme.conicet.gov.ar

\begin{abstract}
Stat3 is a signaling node for multiple oncogenic pathways and is therefore frequently active in breast cancer. As experimental and clinical evidence reveals that progestins are key players in controlling mammary gland tumorigenesis, we studied Stat3 participation in this event. We have previously shown that progestins induce Stat3Tyr705 phosphorylation and its transcriptional activation in breast cancer cells. In this study, we demonstrate that progestins also induce Stat3 phosphorylation at Ser727 residue, which occurs via activation of c-Src/p42/p44 MAPK pathways in murine progestin-dependent C4HD cells and in T-47D cells. Expression of a Stat35727A vector, which carries a serine-to-alanine substitution at codon 727, shows that Stat3Ser727 phosphorylation is required for full transcriptional activation of cyclin D1 gene expression by progestins and for in vivo Stat3 recruitment on cyclin D1 promoter. Transfection of Stat35727A in murine and human breast cancer cells abolished progestin-induced in vitro and in vivo growth. Moreover, we found a positive correlation between progesterone receptor expression and nuclear localization of Stat3Ser727 phosphorylation in breast cancer biopsies. These data highlight Stat3 phosphorylation in Ser727 residue as a nongenomic action by progestins, necessary to promote breast cancer growth.
\end{abstract}

Key Words

- Stat3

- p42/p44 MAPK

- progestin

- breast cancer 


\section{Introduction}

Stat3 belongs to a family of proteins that act as cytoplasmic signaling molecules and transcription factors following nuclear translocation (Bowman et al. 2000, Yu \& Jove 2004). Under physiological conditions, cytoplasmic Stats are phosphorylated (p) on tyrosine residues by tyrosine kinase receptors after binding of growth factors (Silvennoinen et al. 1993, Olayioye et al. 1999) or by soluble tyrosine kinases of the Janus (Jak) and Src kinase families, in the case of cytokine receptor activation (Darnell et al. 1994, Heinrich et al. 1998). pStats form dimers, translocate to the nuclear compartment, bind to specific DNA response elements (i.e. $\gamma$ interferon-activated sequence (GAS) sites), and activate transcription. In normal cells, Stat3 activation is tightly controlled; however, constitutive Stat 3 phosphorylation on tyrosine residues has been found in a wide variety of human tumors (Bowman et al. 2000). In particular, Stat3 plays a key role in mammary cancer by promoting breast tumorigenesis (Yu \& Jove 2004) and conferring resistance to apoptosis (Gritsko et al. 2006) and to chemotherapy (Real et al. 2002).

Accumulated evidence indicates that progestins are implicated in the etiology and pathogenesis of human breast cancer. Clinical observations as well as the recent extensive, randomized, and controlled Women's Health Initiative trial revealed that postmenopausal women who undergo a combined estrogen and progesterone hormone replacement therapy suffer a higher incidence of breast cancer than women who take estrogen alone (Beral 2003). In its classical mechanism of action, the progesterone receptor (PR) acts as a ligand-activated transcription factor on promoters containing progesterone response elements (PREs) (Tsai \& O'Malley 1994). In addition to this direct transcriptional effect, progestins are able to mediate the activation of signal transduction pathways through a rapid or nongenomic mechanism (Migliaccio et al. 1998, Boonyaratanakornkit et al. 2001). Regarding this latter mechanism, it has been described that progestin treatment of human breast cancer cell line T-47D activates the signal-transducing c-Src/p21ras/p42/p44 MAPK cascade to promote cell proliferation (Migliaccio et al. 1998, Ballare et al. 2003). Interestingly, it has been shown that steroid hormone receptors regulate Stat 3 levels and, conversely, Stat3 regulates transcriptional activation of steroid hormones (Richer et al. 1998, De Miguel et al. 2003). We have already demonstrated that progestins induce Stat3 phosphorylation at tyrosine 705 (Tyr705) through the activation of c-Src/Jaks kinases, leading to Stat3 transcriptional activation and proliferation both in mouse and in human mammary breast cancer cells (Proietti et al. 2005). These effects on c-Src and Jaks activation are dependent on the classical PR, evidencing that through a rapid signaling pathway, $\mathrm{PR}$ is able to activate Stat3.

In addition to Tyr705 phosphorylation, a conserved serine phosphorylation site (Ser727) was also identified within the transcriptional activation domain of Stat3. Serine phosphorylation may occur in response to diverse stimuli and it modulates Stat3 transcriptional activity (Wen et al. 1995, Decker \& Kovarik 2000). However, the requirement of Stat3 phosphorylation at Ser727 to achieve a biological effect may vary according to the stimulating ligand and/or cellular context (Sasse et al. 1997). Experiments of replacement of the wild-type (WT) Stat3 allele with the Stat3S727A mutant reveal the importance of Stat3Ser727 phosphorylation in postnatal survival and growth in mice (Shen et al. 2004). Much effort has been made to identify the kinase(s) responsible for serine 727 phosphorylation of Stat3. Stat3Ser727 residue is situated in a conserved PMSP motive that resembles the consensus PXS/TP motive for MAPK targets (Gonzalez et al. 1991). Several kinases activated by a large number of ligands have been implicated in serine phosphorylation, involving an interaction between Stat3 and serine kinase signaling pathways (Decker \& Kovarik 2000). However, Stat3Ser727 phosphorylation induced by progestins and its biological significance remain unexplored.

In this study, we found that progestin treatment of human breast cancer cell line T-47D and of murine progestin-dependent breast cancer C4HD cells induces phosphorylation of Stat3 at Ser727 residue. We also showed that progestin activation of the c-Src/p42/p44 MAPK signaling pathway is directly involved in Stat3Ser727 phosphorylation and contributes to the recruitment of Stat 3 to a GAS site in the cyclin D1 promoter. Prevention of Stat3 phosphorylation at Ser727 residue with a Stat35727A expression vector reveals the importance of this residue in mediating progestin-induced breast cancer cell growth. We also examined 39 primary tumor samples obtained from patients with invasive ductal breast carcinoma and observed a positive correlation between Stat3Ser727 phosphorylation and PR (PGR) expression. As a whole, our data provide evidence that phosphorylation at Ser727 residue confers full transcriptional activity of Stat 3 and that it is a requisite for progestin upregulation of cyclin D1 and in vivo and in vitro breast cancer growth.

Published by Bioscientifica Ltd 


\section{Materials and methods}

\section{Animals and tumors}

Experiments were carried out with virgin female BALB/c mice raised at the Institute of Biology and Experimental Medicine (IBYME) of Buenos Aires, Argentina and were maintained in pathogen-free conditions. All animal studies were conducted as described previously (Proietti et al. 2005) in accordance with the highest standards of animal care as outlined by the NIH Guide for the Care and Use of Laboratory Animals (Guide for the Care and Use of Laboratory Animals 1996) and were approved by the IBYME Animal Research Committee. The hormonedependent ductal tumor line C4HD was originated in mice treated with $40 \mathrm{mg}$ medroxyprogesterone acetate (MPA; Craveri, Buenos Aires, Argentina) every 3 months for 1 year and has been maintained by serial transplantation in animals treated with $40 \mathrm{mg}$ s.c. MPA depot in the opposite flank to tumor inoculum (Balana et al. 1999). C4HD tumor line expresses PR and estrogen receptor (ER) and lacks glucocorticoid receptor expression (Balana et al. 1999, Lanari et al. 1999).

\section{Cell culture, treatments, and proliferation assays}

Primary culture of epithelial cells from C4HD tumors was performed as described previously (Rivas et al. 2008). Cells were incubated in DMEM-Ham F12 (DMEM:F12) 1:1 v/v (without phenol red) supplemented with $0.1 \%(\mathrm{v} / \mathrm{v})$ charcolized FCS (ChFCS) in the presence or absence of $10 \mathrm{nM}$ MPA (Sigma) and $10 \mathrm{nM}$ RU486 (Sigma). T-47D cells were obtained from the American Type Culture Collection and maintained in DMEM:F12+10\% FCS. $\mathrm{T}-47 \mathrm{D}-\mathrm{Y}$ cells were a generous gift from $\mathrm{K}$ Horwitz (University of Colorado Health Sciences Center, Denver, CO, USA; Sartorius et al. 1994). When indicated, cells were pretreated for $90 \mathrm{~min}$ with $10 \mu \mathrm{M}$ U0126 (Sigma) or with 4-amino-5-(4-chlorophenyl)-7-(t-butyl)pyrazolo[3,4-D] pyrimidine (PP2) $10 \mu \mathrm{M}$ (Calbiochem, San Diego, CA, USA) dissolved in 1:2000 dimethyl sulfoxide, or dasatinib $10 \mu \mathrm{M}$ (LC Laboratories, Woburn, MA, USA), to block p42/p44 MAPK signaling pathway or c-Src activity respectively before the addition of MPA. Controls were performed in order to verify that dimethyl sulfoxide (1:2000) did not modify MPA-modulated c-Src tyrosine phosphorylation, p42/p44 MAPK, or Ser727Stat3 phosphorylation. Cell proliferation was evaluated by a $\left[{ }^{3} \mathrm{H}\right]$ thymidine incorporation assay as described previously (Proietti et al. 2005). Assays were performed in octuplicate.
In former experiments, we have demonstrated that thymidine uptake correlates with the number of cells per well (Rivas et al. 2008). Proliferation was also evaluated by propidium iodide staining and flow cytometry analysis, as described previously (Rivas et al. 2010). Cell cycle analysis was performed using a FACScalibur flow cytometer (Becton-Dickinson, La Jolla, CA, USA) and Modfit LT Software.

\section{Western blot analysis}

Lysates were prepared from cells subjected to the different treatments described, and proteins were subjected to SDS-PAGE as described previously (Schillaci et al. 2006). Membranes were immunoblotted with the following antibodies: total Stat3 (C-20), pp42/p44 MAPK (E-4), total p42/p44 MAPK (C-14), all from Santa Cruz Biotechnology; pStat3Ser727 (GE4), phosphotyrosine c-Src (Tyr 416), and c-Src (36D10) from Cell Signaling (Beverly, MA, USA); PR (clone hPRa7), actin (clone ACTN05), and cyclin D1 from Neomarkers (Freemont, CA, USA); and $\beta$-tubulin from Sigma. The specificity of pStat3Ser727 (GE4) antibody for western blot (WB) assays was previously reported (Sud et al. 2009, Turner et al. 2009). Human and mouse Stat3 homologies are completely identical, except for a single amino acid change at position 760 (Pietra et al. 1998).

The NE-PER nuclear and cytoplasmic extraction reagent technique (Thermo Fisher Scientific, Inc., Rockford, IL, USA) was performed according to manufacturer's instructions and the subcellular extracts were subjected to SDS-PAGE and immunoblotting.

\section{Transient transfections}

C4HD or T-47D cells were transiently transfected for $48 \mathrm{~h}$ with $2 \mu \mathrm{g}$ of the expression vectors for Stat3S727A (pcDNA5/FRT vector encoding a GFP-Stat3 fusion protein that carries a serine-to-alanine substitution at codon 727-GFP-Stat3S727A) and WT Stat3 (pcDNA5/FRT vector encoding a GFP-Stat3 fusion protein) (Lee et al. 2009). As control, cells were transfected with $2 \mu \mathrm{g}$ of the empty vector (pcDNA5/FRT). All these vectors were kindly provided by $\mathrm{H} \mathrm{Yu}$ (Beckman Research Institute, Duarte, CA, USA). Transfection efficiencies, evaluated by the percentage of cells that exhibited GFP $48 \mathrm{~h}$ after transfection, varied between 60 and 70\%. C4HD cells were transfected in DMEM-F12 supplemented with $10 \mathrm{nM}$ MPA and 2.5\% ChFCS, and T-47D cells were transfected in DMEM with 10\% ChFCS without antibiotics with

Published by Bioscientifica Ltd. 
Fugene HD transfection reagent (Roche Biochemicals). The plasmid encoding human WT hPR-B was kindly provided by $\mathrm{K}$ Horwitz. Mutant PR-B engineered to convert three key prolines (P422A, P423A, and P426A) to alanines (PR-BmPro), thus abolishing PR binding to all the SH3 domains and inhibiting activation of the Src family tyrosine kinases (Boonyaratanakornkit et al. 2001), was generously provided by D Edwards (Baylor College of Medicine, Houston, TX, USA). After transfection, cells were washed and cultured for $24 \mathrm{~h}$ in $0.1 \%$ ChFCS before treatment with MPA for the indicated times. Total cell lysates were then prepared as described earlier for use in WB assays. To investigate the capacity of MPA to induce the transcriptional activation of Stat3, C4HD and T-47D cells were transiently transfected for $48 \mathrm{~h}$ with $2 \mu \mathrm{g}$ of a luciferase reporter plasmid containing four copies of the m67 high-affinity binding site (Bromberg et al. 1999, Zhang et al. 2000) or with a luciferase reporter plasmid containing the cyclin D1 human promoter region (1745 cyclin D1-luc), kindly provided by R Pestell (Northwestern University Medical School, Chicago, IL, USA). Cells were co-transfected with $10 \mathrm{ng}$ Renilla luciferase expression vector CMV-pRL (Promega) to correct variations in transfection efficiency. Transfected cells were lysed and luciferase assays carried out using the Dual-Luciferase Reporter Assay System (Promega).

\section{Chromatin immunoprecipitation assays}

Chromatin immunoprecipitation (ChIP) was performed as we described previously (Beguelin et al. 2010). Briefly, chromatin was sonicated to an average of about $500 \mathrm{bp}$. Sonicated chromatin was then immunoprecipitated using $4 \mu \mathrm{g}$ Stat 3 antibody and IgG as control. The immunoprecipitate was collected using protein A beads (Millipore, Temecula, CA, USA), which were washed repeatedly to remove nonspecific DNA binding. Chromatin was eluted from the beads, and cross-links were removed overnight at $65^{\circ} \mathrm{C}$. DNA was then purified and quantified using realtime PCR performed with an ABI Prism 7500 sequence detector, using SYBR green PCR master mix (Applied Biosystems). Primers used were as described previously (Beguelin et al. 2010). PCR was performed for 40 cycles with $15 \mathrm{~s}$ of denaturing at $95^{\circ} \mathrm{C}$ and annealing and extension at $60^{\circ} \mathrm{C}$ for $1 \mathrm{~min}$.

\section{In vitro cold phosphorylation assay}

T-47D cells were treated with $10 \mathrm{nM}$ MPA for 2 min or preincubated for $90 \mathrm{~min}$ with $10 \mu \mathrm{M}$ U0126 before MPA stimulation. Cells were lysed in kinase lysis buffer $(20 \mathrm{mM}$ HEPES, pH 7.5, $10 \mathrm{mM}$ EGTA, 1\% NP-40, and $2.5 \mathrm{mM}$ $\mathrm{MgCl}_{2}$ ) and MAPK was immunoprecipitated using antitotal p42/p44 MAPK antibody (C-14; Santa Cruz) from $500 \mu \mathrm{g}$ protein extracts. Unphosphorylated Stat3 was immunoprecipitated from $500 \mu \mathrm{g}$ protein extract from nontreated C4HD cells using the Stat 3 antibody (C-20, Santa Cruz). The immunoprecipitated Stat3 was then subjected to an in vitro phosphorylation assay with p42/p44 MAPKs immunoprecipitated from cells subjected to each of the treatments described, following the procedure previously described (Rivas et al. 2010). Gels were transferred onto nitrocellulose. Their upper part was immunoblotted with pStatSer727 antibody while their lower part was revealed with an anti-pp42/p44 MAPK MAB. Filters were then stripped and hybridized with anti-total Stat3 or anti-total p42/p44 MAPK antibodies respectively.

\section{siRNAs transfections}

siRNAs targeting PR were synthesized by Dharmacon, Inc. (Lafayette, CO, USA; PR siRNA 5'-AUAGGCGAGACUACAGACGUU-3'). A nonsilencing siRNA oligonucleotide from Dharmacon, Inc. that does not target any known mammalian gene was used as a negative control. The transfection of siRNA duplex was performed for 3 days using DharmaFECT transfection reagent according to manufacturer's directions.

\section{Immunofluorescence and confocal microscopy}

T-47D cells grown on glass coverslips were fixed and permeabilized in ice-cold methanol and were then blocked with PBS with $1 \%$ BSA. pStat3Ser727 was localized using a mouse monoclonal (6E4) antibody (Cell Signaling) followed by incubation with a goat anti-mouse IgG-Alexa 488 (Molecular Probes, Eugene, OR, USA) secondary antibody. Negative controls were carried out using PBS instead of primary antibodies. Approximately 100-200 cells were analyzed for each treatment, of which around $80 \%$ showed the same pattern of Stat 3 phosphorylation and cellular localization. Cells were analyzed using a Nikon Eclipse E800 confocal laser microscopy system (Beguelin $e t$ al. 2010). Nuclei were stained with propidium iodide.

\section{In vivo inhibition of Stat3Ser727 phosphorylation}

C4HD cells were transiently transfected with the Stat3S727A expression vector or with the empty vector. After transfection, $10^{6}$ cells from each experimental group

Published by Bioscientifica Ltd 
were inoculated s.c. into animals treated with a $40 \mathrm{mg}$ MPA depot in the flank opposite of the cell inoculum $(n=5)$. Tumor growth was measured three times a week with a vernier caliper. Tumor volume $\left(\mathrm{mm}^{3}\right)$ was calculated as $\left(L \times W^{2}\right) / 2$, where $L$, length $(\mathrm{mm})$ and $W$, width $(\mathrm{mm})$. Tumor growth rates were determined as the slopes of growth curves. Linear regression analysis was performed on tumor growth curves, and the slopes were compared using ANOVA followed by a parallelism test to evaluate the statistical significance of differences.

\section{Patients and tissue microarrays}

Paraffin-embedded tissue samples from 48 archived invasive breast carcinomas were selected for construction of tissue microarray (TMA) blocks from the files of the Instituto de Oncología Henry Moore (Buenos Aires, Argentina), from 2001 to 2008. From nine tumor samples, immunohistochemical analysis of nuclear pStat3Ser727 levels was uninformative because of missing or unrepresentative samples in the array sections analyzed. All patients were treated with surgery. This study was conducted with the approval of ethics committees of IBYME and the Instituto de Oncología Henry Moore and informed written consents were obtained from all patients before inclusion. Pretreatment patient staging was classified according to the system of the American Joint Committee on Cancer (AJCC; Singletary et al. 2002) through the Elston and Ellis histological grading (Page et al. 1995). TMAs were constructed as described earlier (Schillaci et al. 2012).

\section{Immunofluorescence and immunohistochemistry analysis of TMAs}

Immunofluorescence was performed as described previously (Schillaci et al. 2012), using the mouse monoclonal anti-pStat3Ser727 (6E4) antibody (dilution 1:50 overnight at $4{ }^{\circ} \mathrm{C}$; Cell Signaling). Slides were then incubated with an anti-mouse Alexa 488-conjugated antibody (1:1000, Molecular Probes). Nuclei were stained with propidium iodide. Slides were analyzed by Nikon Eclipse E800 confocal laser microscopy system. Negative controls were carried out in the absence of primary antibodies. Staining intensity was graded on the following scale: 0 , no staining; 1 , weak staining; 2, moderate staining; and 3 , intense staining, as previously used for nuclear pTy705Stat 3 classification by other authors (Dolled-Filhart et al. 2003, Sato et al. 2011). Scoring of the TMA was completed by two independent observers (E Maronna and P Guzmán), with very high correlation between scorers. Discrepancy between them was averaged to get a single final score. A score of one or more was required for tumor sample to be considered positive for nuclear pStat3Ser727 expression (Sato et al. 2011). ER and PR were evaluated by immunohistochemistry (IHC) with clone 6F11 (Novocastra Laboratories, UK) and clone hPRa2 $+\mathrm{hPRa} 3$ (NeoMarkers) respectively and scored as described (Schillaci et al. 2012).

\section{Statistical analysis}

WB bands were quantified using Image J (NIH, Bethesda, MA, USA), phosphorylated protein band values were normalized to total protein bands, and cyclin D1 bands were normalized to $\beta$-tubulin bands. Differences between control and experimental groups along this work were analyzed by ANOVA followed by Tukey's $t$-test between groups. A $P<0.05$ was accepted as statistically significant. Analyses of clinical data were conducted using SPSS Software version 17.0 (SPSS, Inc., Chicago, IL, USA). Correlations between categorical variables were performed using the Fisher's exact test.

\section{Results}

MPA induces Stat3Ser727 phosphorylation acting through the classical PR

In this study, we used the progestin-dependent C4HD tumor from an experimental model of hormonal carcinogenesis in which the synthetic progestin MPA induces mammary adenocarcinomas in female BALB/c mice (Proietti et al. 2005). We have long demonstrated that MPA is able to induce tyrosine phosphorylation of Stat 3 in C4HD cells and in the human breast cancer cell line T-47D (Proietti et al. 2005). We here evaluated Ser727 phosphorylation in C4HD and T-47D cells in response to MPA. As shown in Fig. 1A, MPA induced Stat3Ser727 phosphorylation within $5 \mathrm{~min}$ of treatment and remained elevated at $30 \mathrm{~min}$ in C4HD and T-47D cells. This effect was completely abolished by the progestin antagonist RU486 or by knockdown of $P R$ gene expression with $P R$ siRNAs in C4HD cells (Fig. 1B). Moreover, in human PR null T-47D-Y cells, MPA treatment did not induce Stat3Ser727 phosphorylation (Fig. 1C). On the other hand, transfection of these cells with PR-B (T-47D-YPR-B) restores MPA ability to phosphorylate Stat3 at Ser727 residue (Fig. 1C). These results indicate that MPA regulates the rapid phosphorylation of Stat3Ser727 residue through the classical PR.

Published by Bioscientifica Ltd. 
A
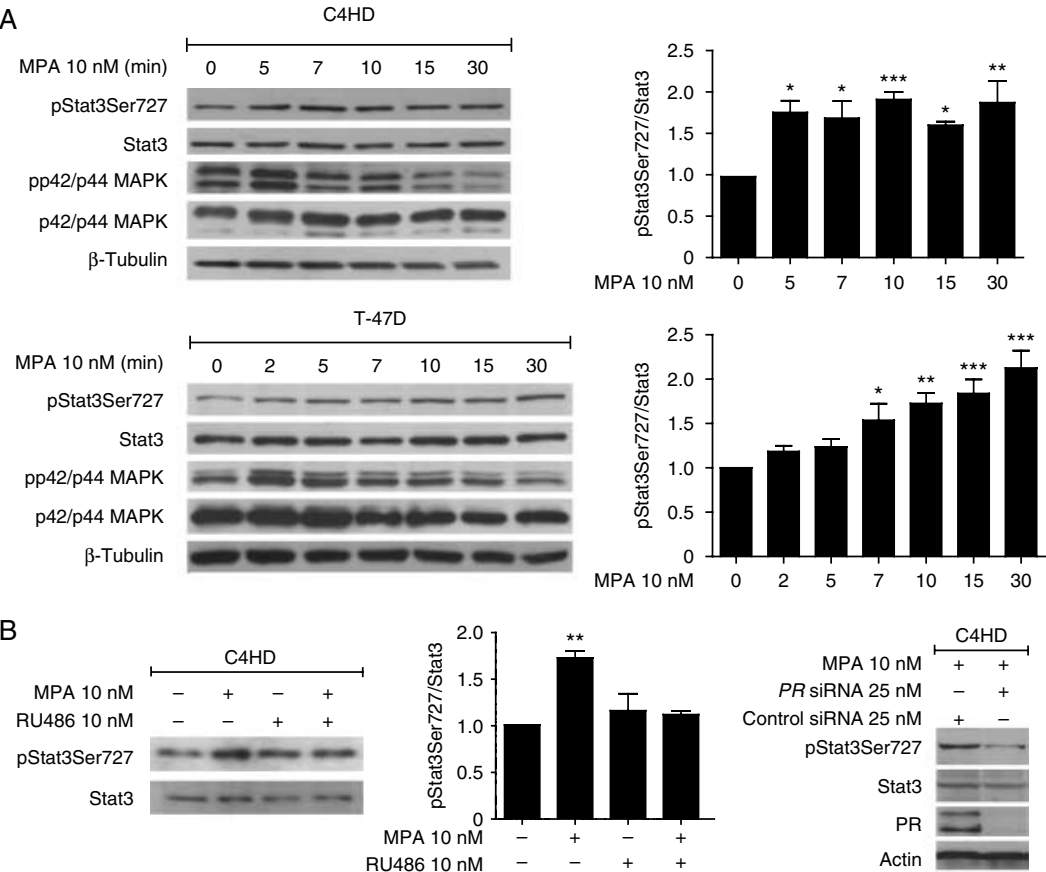

C

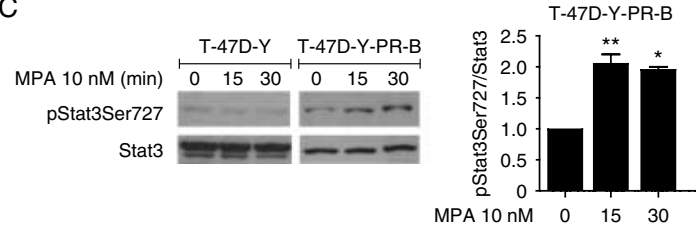

Figure 1

MPA induces Stat3Ser727 phosphorylation through the classical PR. (A) MPA induces Stat3 phosphorylation on Ser727. C4HD cells (upper panel) or T-47D cells (lower panel) were treated with MPA for different time points. Western blots (WB) were performed with pStat3Ser727 or pp42/p44 MAPK antibodies, and filters were reprobed with total Stat3 and p42/p44 MAPK antibodies. $\beta$-Tubulin is shown as loading control. Data analysis showed that the increases in p42/p44 MAPK phosphorylation in cells treated with MPA compared with the levels of nontreated cells were significant $(P<0.001)$. (B and $C)$ MPA-induced Stat3Ser727 phosphorylation is mediated via the classical PR. (B) C4HD cells were treated with MPA for 10 min or pretreated with RU486 for 90 min before MPA treatment (left). C4HD cells were transfected with PR siRNA or control siRNA before MPA

\section{MPA induces Stat3Ser727 phosphorylation through the activation of c-Src/p42/p44 MAPK signaling pathway}

It is known that progestins induce rapid c-Src activation in mammary tumor cells, including our C4HD tumor model (Migliaccio et al. 1998, Boonyaratanakornkit et al. 2001, Proietti et al. 2005). Pioneering works defined the proline-rich domain of human PR as an absolute requirement for interaction with c-Src (Boonyaratanakornkit et al. 2001) and consequent c-Src activation of signaling cascades in response to progestins (Migliaccio et al. 1998, stimulation (10 min; right). WB were performed with pStat3Ser727 antibodies, and filters were reprobed with total Stat3 antibodies. WB shows the effects of siRNAs on PR expression. Data analysis showed that the inhibition of MPA-induced Stat3 phosphorylation levels caused by $P R$ siRNA was significant $(P<0.001)$. (C) T-47D-Y cells were treated with MPA or were transfected with the PR-B isoform before MPA treatment. In all cases, bands were quantified using Image $J$ and phospho-protein band values were normalized to total protein bands. Nontreated cell samples were set as 1.0. (A, B and C) Signal intensities of phospho-Stat3Ser727 bands normalized to total Stat3 bands are graphically represented in bar plots $(* P<0.05$,

$* * P<0.01$, and $* * * P<0.001)$. Data are presented as mean \pm s.E.M. of three experiments.

Boonyaratanakornkit et al. 2001). To explore whether c-Src was involved in progestin-mediated Stat3Ser727 phosphorylation, we transfected $\mathrm{T}-47 \mathrm{D}-\mathrm{Y}$ cells with the PR-BmPro mutant, in which three prolines (P422A, $\mathrm{P} 423 \mathrm{~A}$, and $\mathrm{P} 427 \mathrm{~A}$ ) were converted to alanines (T-47D-YPR-BmPro cells). Figure 2A shows that T-47D-Y-PR-BmPro cells lacked the ability to phosphorylate Stat3 at Ser727 residue in response to MPA, suggesting that progestinactivated c-Src acts as an upstream activator of Stat3. Moreover, the addition of the c-Src inhibitors PP2 or

Published by Bioscientifica Ltd. 
A

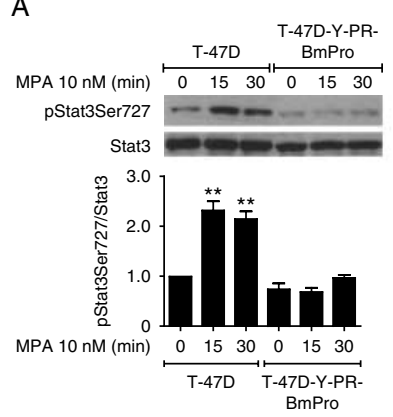

C
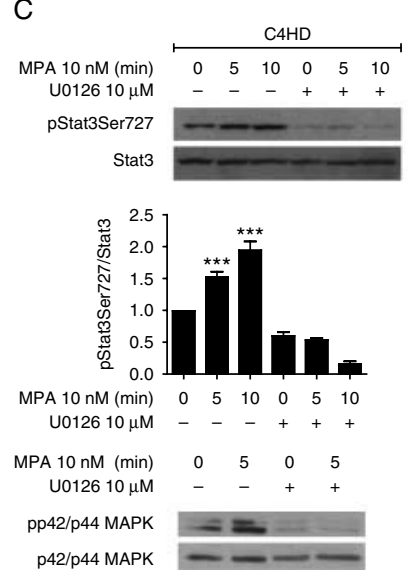

B
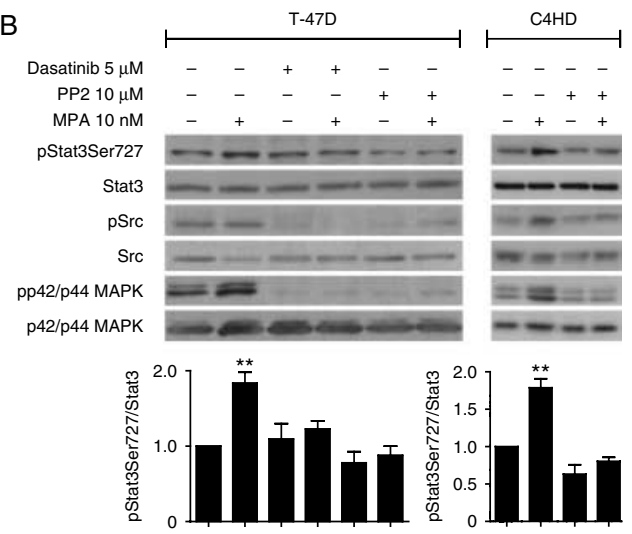

Dasatinib $5 \mu \mathrm{M}$

PP2 $10 \mu \mathrm{M}$

MPA $10 \mathrm{nM}$
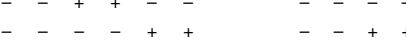

D

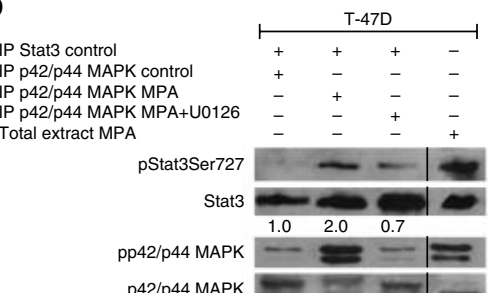

p42/p44 MAPK

\section{Figure 2}

MPA induces Stat3Ser727 phosphorylation through Src/p42/p44 MAPK activation pathway. (A and B) c-Src mediates MPA-induced p42/p44 MAPK activation that leads to Stat3Ser727 phosphorylation. (A) T-47D-Y cells were transfected with the PR-BmPro mutant and were then treated with MPA T-47D cells are shown as Stat3Ser727 phosphorylation control. (B) T-47D cells were treated with MPA for $15 \mathrm{~min}$ (pStat3Ser727) or $2 \mathrm{~min}$ (pSrc and pp42/p44 MAPK) or preincubated for $90 \mathrm{~min}$ with PP2 or dasatinib before MPA treatment (left panel). C4HD cells were treated with MPA for $10 \mathrm{~min}$ or preincubated for 90 min with PP2 before MPA treatment (right panel). WB were performed with phospho-antibodies, and filters were reprobed with the respective total protein antibody. (C and D) p42/p44 MAPK mediates MPA-induced Stat3Ser727 phosphorylation. (C) C4HD cells were treated with MPA or preincubated for 90 min with U0126 before MPA treatment. WB were performed against pStat3Ser727 (upper panel) and pp42/44 MAPK (lower panel) and filters were reprobed with the respective total protein antibody. (A, B and C) In all cases, bands were quantified using Image $\mathrm{J}$ and phospho-protein bands values were normalized to total

dasatinib effectively inhibited Stat3Ser727 phosphorylation by MPA in T-47D cells (Fig. 2B). Although it is known that murine PR lacks the polyproline sequence known to interact with c-Src, we have previously demonstrated that MPA treatment for $2-10$ min of murine C4HD cells induced strong c-Src tyrosine phosphorylation (Proietti et al. 2005). Interestingly, blockage of MPA-induced c-Src activation by PP2 treatment in C4HD cells leads to inhibition of Stat3Ser727 phosphorylation in these murine cells (Fig. 2B). protein bands. Nontreated cell samples were set as 1.0. Signal intensities of phospho-Stat3Ser727 bands normalized to total Stat3 bands are graphically represented in bar plots ( $* * P<0.01$ and $* * * P<0.001)$. Data are presented as mean \pm s.E.M. of three experiments. Data analysis showed that the increases in p42/p44 MAPK and c-Src phosphorylation in cells treated with MPA compared with the levels of nontreated cells were significant $(P<0.001)$. (D) A cold in vitro phosphorylation assay was performed with T-47D cells preincubated or not with U0126 and then treated with MPA for 2 min. p42/p44 MAPK was immunoprecipitated from each treatment and Stat3 immunoprecipitated from nontreated T-47D cells was used as substrate. Shown are WBs of Stat3, anti-phospho-Stat3Ser727, antiphospho-p42/p44 MAPK, and p42/p44 MAPK. Signal intensities of phospho-Stat3Ser727 bands were analyzed by densitometry and normalized to total immunoprecipitated Stat3 bands. Nontreated cell samples were set as 1.0. This experiment was repeated three times with similar results. IP, immunoprecipitation.

p42/p44 MAPK are serine/threonine kinases whose activation by progestin-induced c-Src signaling is well acknowledged (Migliaccio et al. 1998, Ballare et al. 2003). However, the role of $\mathrm{p} 42 / \mathrm{p} 44$ MAPK in progestininduced Stat 3 activation has never been addressed. Here, we confirmed that MPA induces a rapid phosphorylation of p42/p44 MAPK in C4HD and T-47D cells. MPA-induced activation was observed as early as $2-5 \mathrm{~min}$ after treatment and preceded Stat3 serine phosphorylation (Fig. 1A). Pretreatment of C4HD cells with $10 \mu \mathrm{M}$ U0126, a p42/p44

Published by Bioscientifica Ltd 
MAPK pathway inhibitor, suppressed phosphorylation of Stat3 at Ser727 residue (Fig. 2C). Blockade of c-Src activation by addition of dasatinib or PP2 abolished p42/p44 MAPK in T-47D cells. Similar results were obtained in C4HD cells treated with PP2, suggesting that MAPK phosphorylation is dependent on c-Src activation also in murine cells (Fig. 2B).

To further support our finding that the serine phosphorylation of Stat 3 proceeds though the activation of p42/p44 MAPK-dependent pathway, we performed a cold in vitro phosphorylation assay. For this purpose, we immunoprecipitated p42/p44 MAPK from T-47D cells treated or not with MPA for 2 min and from T-47D cells pretreated with U0126 for 90 min before MPA treatment. We also immunoprecipitated Stat3 from unstimulated cells and used it as a source of unphosphorylated Stat3 in the assay. As shown in Fig. 2D, incubation of p42/p44 MAPK immunoprecipitated from T-47D cells treated with MPA with the unphosphorylated Stat3 induced phosphorylation of Stat3 at Ser727 residue. Neither p42/p44

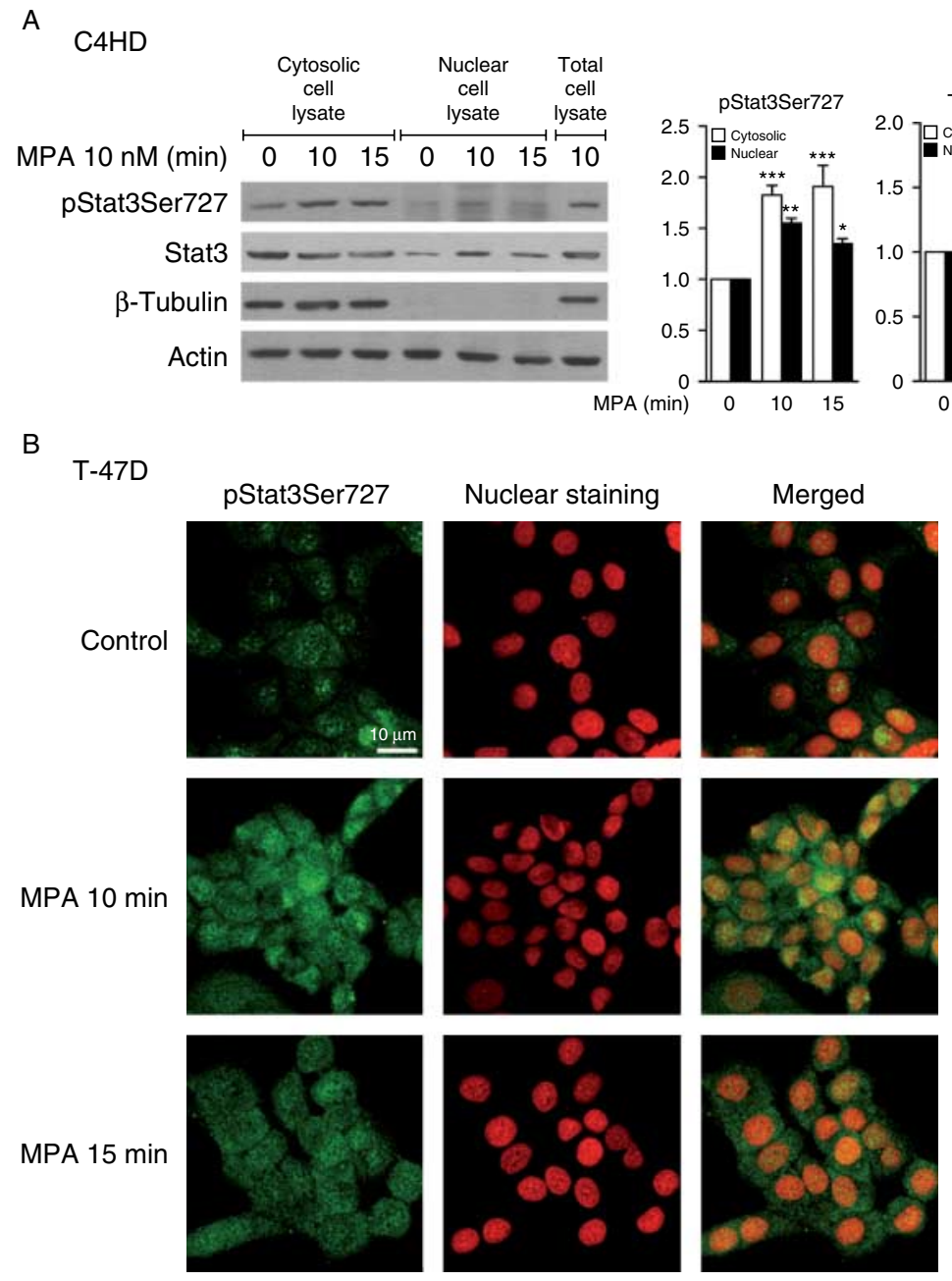

Figure 3

MPA effects on Stat3Ser727 cellular localization. (A) C4HD cells were treated with MPA for 10 and $15 \mathrm{~min}$, and nuclear and cytosolic protein extracts were analyzed by WB. pStat3Ser 727 blot was reprobed with a Stat3 antibody. Total cell lysates treated with MPA were blotted in parallel. $\beta$-Tubulin was used to control cellular fractionation efficiency. Bands were quantified using Image $J$ and values of nuclear and cytosolic protein bands were normalized to actin. Fold changes in nuclear and cytosolic phosphoStat3Ser727 and total Stat3 are graphically represented in bar plots $\left({ }^{*} P<0.05,{ }^{*} P<0.01\right.$, and $\left.* * * P<0.001\right)$. Data are presented as mean \pm S.E.M. of three experiments. (B) T-47D cells were treated with $10 \mathrm{nM}$ MPA for 10 and $15 \mathrm{~min}$ and pStat3Ser727 (green) was localized by immunofluorescence and confocal microscopy. Nuclei were stained with propidium iodide (red). Merged images show nuclear localization of pStat3Ser727 at 10 and 15 min of MPA treatment. The experiments were repeated five times, with similar results. http://erc.endocrinology-journals.org DOI: $10.1530 /$ ERC-12-0194
(C) 2013 Society for Endocrinology Printed in Great Britain 
MAPK obtained from control cells nor p42/p44 MAPK inactivated by U0126 increased Stat3 phosphorylation (Fig. 2D). As a whole, these results strongly suggest that p42/p44 MAPK are the kinases activated by MPA responsible for the induction of Stat3 phosphorylation at Ser727 residue.

\section{MPA promotes nuclear localization of Stat3 phosphorylated at Ser727}

We have already reported that MPA induces Stat3Tyr705 phosphorylation and its nuclear translocation (Proietti et al. 2005). In order to investigate the localization of Stat3 phosphorylated in Ser727 induced by MPA, nuclear and cytoplasmic extracts from C4HD were prepared and evaluated by WB. Figure 3A shows that MPA treatment induced Stat3Ser727 phosphorylation in the cytoplasmic fraction and an increased translocation to the nuclear compartment (Fig. 3A). In addition, immunofluorescence staining and confocal microscopy studies in T-47D revealed that Stat3 phosphorylated at Ser727 is barely detected in control cells. MPA treatment for 10 or $15 \mathrm{~min}$ resulted in strong staining of pStat3Ser 727 both in the cytosol and in the nuclear compartment (Fig. 3B).

\section{MPA requires Stat3Ser727 phosphorylation to achieve maximal transcriptional activation of Stat3}

To address the question of whether serine phosphorylation influences the transcriptional activity of Stat3, C4HD cells were transiently co-transfected with Stat3S727A expression vector, which carries a serineto-alanine substitution at codon 727 , together with a luciferase reporter plasmid containing four copies of the m67 high-affinity binding site (4xm67-tk-luc; Bromberg et al. 1999). As controls, cells were co-transfected with WT Stat3 expression vector or with an empty vector, together with the reporter plasmid. As previously described, MPA stimulation induced Stat 3 transcriptional activation of Stat3 (Proietti et al. 2005; Fig. 4A). Transfection of C4HD cells with Stat3S727A inhibited the capacity of MPA to activate the m67-Luc reporter plasmid (Fig. 4A). These data indicate that Stat3Ser727 phosphorylation is required for MPA-induced maximal Stat3 activation. WB studies demonstrated similar expression of Stat3WT and Stat3S727A in C4HD transfected cells (Fig. 4A, right panel).

To explore the biological relevance of Stat3Ser727 phosphorylation, we studied cyclin D1 promoter activation, as it is a key breast cancer cell cycle regulator, whose promoter has Stat3 biding sites (Leslie et al. 2006) and lacks a PRE in its 1-kb promoter-proximal region (Skildum et al. 2005). C4HD and T-47D cells were transiently transfected with a 1745 bp human cyclin D1 promoter luciferase construct containing Stat 3 binding sites, named GAS sites, at positions $-984,-568,-475$, $-239,-68$, and -27 . Cells were co-transfected either with an empty vector, or a Stat3WT or a Stat3S727A expression vector. MPA treatment of both cell types resulted in an increase in cyclin D1 promoter activity in cells transfected with an empty vector or with Stat3WT vector (Fig. 4B). On the other hand, transfection of cells with Stat3S727A absolutely inhibited the effects of MPA on cyclin D1 promoter activation in both cell types (Fig. 4B). The reporter assays shown in Fig. 4A and $\mathrm{B}$ suggest that Stat3S727A vector is acting as a dominant negative of endogenous Stat3.

Finally, we sought to determine the participation of Stat3Ser727 phosphorylation in the upregulation of cyclin D1 protein expression by MPA. Abolishment of Stat3Ser727 phosphorylation by transfection with Stat3S727A abrogated MPA-induced cyclin D1 expression in C4HD and T-47D cells (Fig. 4C). As a whole, our results indicate that Stat3 requires Ser727 phosphorylation to achieve full transcriptional activity on cyclin D1 promoter and protein expression upon MPA stimulation in breast cancer cells.

\section{Stat3Ser727 phosphorylation is required for in vivo binding of Stat3 to the promoter of cyclin D1}

To assess the participation of Stat3Ser727 phosphorylation on the specific association of Stat 3 to its binding sites in the context of living cells, we used a ChIP assay. After $30 \mathrm{~min}$ of MPA treatment, chromatins were immunoprecipitated using a total Stat3 antibody. Our findings with T-47D cells transfected with an empty vector or with Stat3WT, using primers spanning the GAS site at position -948 of the human cyclin D1 promoter, showed a significant and specific MPA-induced binding of Stat3 (Fig. 4D), as was previously reported by our laboratory (Beguelin et al. 2010). We then questioned whether Stat3 phosphorylation in Ser727 is mandatory for Stat3 recruitment to the GAS sites of the cyclin D1 promoter. To address this issue, we transfected T-47D cells with a Stat3S727A expression vector. We observed that the absence of Stat3Ser727 phosphorylation blocked Stat3 occupancy of the GAS sites of cyclin D1 promoter. These results reveal that Stat 3 phosphorylation in serine 727 residue is necessary for in vivo Stat3 recruitment to the cyclin D1 promoter after MPA treatment.

Published by Bioscientifica Ltd. 
A
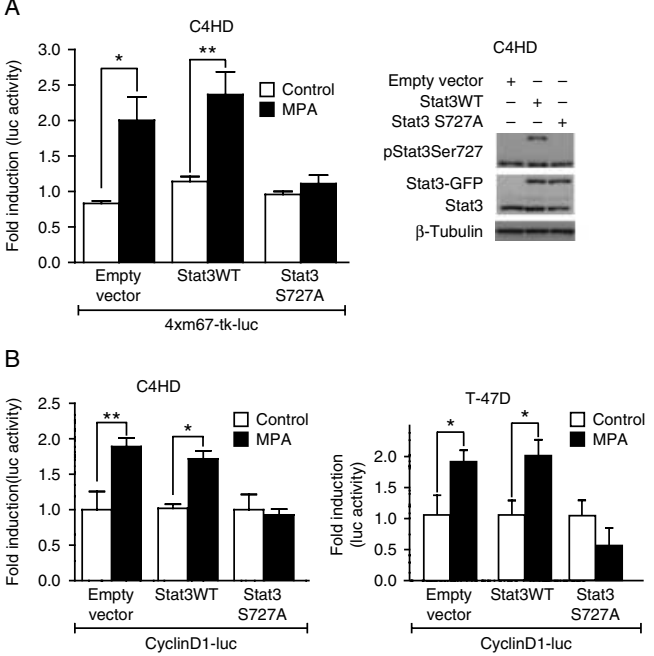

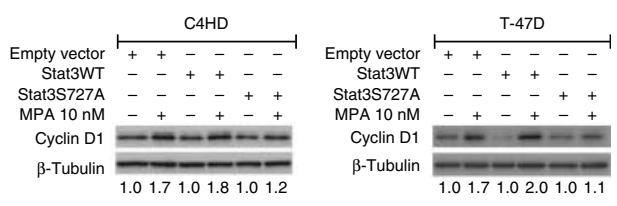

D

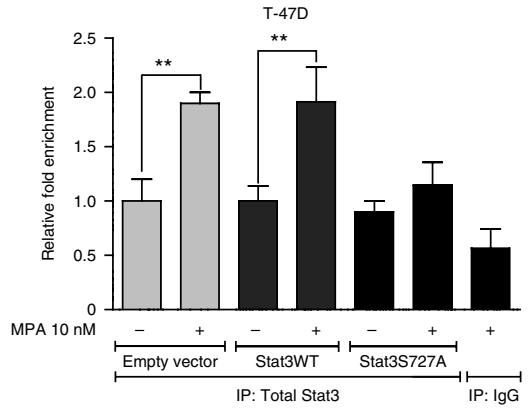

\section{Figure 4}

Serine 727 phosphorylation of Stat3 is a requirement for MPA-induced Stat3 full transcriptional activation. (A) C4HD cells were transfected with a luciferase reporter plasmid containing four copies of the m67 high-affinity binding site (4xm67-tk-luc) and a Renilla expression vector as an internal control. Cells were co-transfected with the empty vector (pcDNA 5/FRT) or Stat3WT or Stat35727A expression vectors. After transfection, cells were treated with MPA for $24 \mathrm{~h}$. Results are presented as the fold induction of luciferase activity with respect to control cells not treated with MPA. Data shown represent the mean data from three independent experiments for each cell type \pm S.E.M. Results are presented as the fold induction of luciferase activity with respect to cells without MPA treatment. Statistical significances are calculated against cells without MPA treatment $\left({ }^{*} P<0.05\right.$ and $* * P<0.01)$. (B) MPA induces cyclin D1 promoter activation via Stat3Ser727 phosphorylation. Cells were transfected with a 1745 bp length human cyclin D1 promoter luciferase construct, which contains Stat3 binding sites (GAS) and lacks progesterone-responsive elements (PRE) (cyclin D1-luc). Cells were co-transfected with the empty vector or Stat3WT or Stat35727A expression vectors. After transfection, cells were treated with MPA for $24 \mathrm{~h}$. Results are presented as the fold induction of luciferase activity with respect to control cells not treated with MPA. Data shown represent the mean data from three independent experiments for each cell type \pm s.E.M. Statistical significances are calculated against control cells

\section{Blockade of Stat3Ser727 phosphorylation inhibits in vitro and in vivo progestin-induced breast cancer growth}

These results led us to investigate the correlation between MPA-induced Stat3Ser727 phosphorylation and cell growth. Thus, C4HD and T-47D cells were transiently transfected with Stat3WT or Stat3S727A expression vectors or with the corresponding empty vector, and proliferation was evaluated by $\left[{ }^{3} \mathrm{H}\right]$-thymidine incorporation at 48 or $24 \mathrm{~h}$ of MPA treatment respectively. As shown in Fig. 5A, expression of the Stat3S727A mutant had an inhibitory effect on MPA-induced proliferation of both human and murine breast cancer cells, compared with MPA-stimulated cells transfected with Stat3WT or an empty vector. Proliferation of transfected
( $* P<0.05$ and $* * P<0.01)$. (C) MPA induces cyclin D1 protein expression via Stat3Ser727 phosphorylation. T-47D and C4HD cells were transfected with the empty vector or Stat3WT or Stat3S727A expression vectors and were then treated with MPA for $24 \mathrm{~h}$. Cyclin D1 protein expression was analyzed by WB. Bands were quantified using Image $J$ and cyclin D1 protein values were normalized to $\beta$-tubulin. Nontreated cell samples were set as 1.0. These experiments were repeated four times with similar results. Data analysis showed that the increases in cyclin D1 expression induced by MPA treatment in cells transfected with the empty vector and with Stat3WT compared with the levels of nontreated cells and the inhibition of MPA effect caused by transfection with Stat35727A were significant $(P<0.01)$. (D) MPA induces in vivo binding of Stat3 to the cyclin D1 promoter via pStat3Ser727. Recruitment of Stat3 to the cyclin D1 promoter was analyzed by ChIP of cells transfected with the empty vector or Stat3WT or Stat35727A expression vectors and treated with MPA for $30 \mathrm{~min}$. DNA was immunoprecipitated with total Stat3 antibody and was amplified by qPCR using primers flanking the GAS sites. The arbitrary qPCR number obtained for each sample was normalized to the input, setting the value of the nontreated sample as 1 . Data are expressed as fold chromatin enrichment over nontreated cells $(* * P<0.01)$. Experiments were repeated three times with similar results.

T-47D was also evaluated by propidium iodide staining and flow cytometry analysis, with similar results. Expression of Stat3S727A had an inhibitory effect on MPA-induced growth of T-47D cells, reflected in a cell cycle arrest in phase G1 compared with Stat3WTtransfected T-47D cells in the presence of MPA (Fig. 5B).

Furthermore, we wanted to explore Stat3Ser727 requirement for in vivo progestin-driven breast cancer growth, for which we took advantage of the well-described model of murine breast cancer tumor C4HD that requires progestin for in vivo growth in BALB/c mice (Beguelin et al. 2010). C4HD cells growing in $10 \mathrm{nM}$ MPA were transfected with Stat3S727A expression vector or with an empty vector. After $48 \mathrm{~h}$ of transfection, $10^{6}$ cells from each

Published by Bioscientifica Ltd. 
A
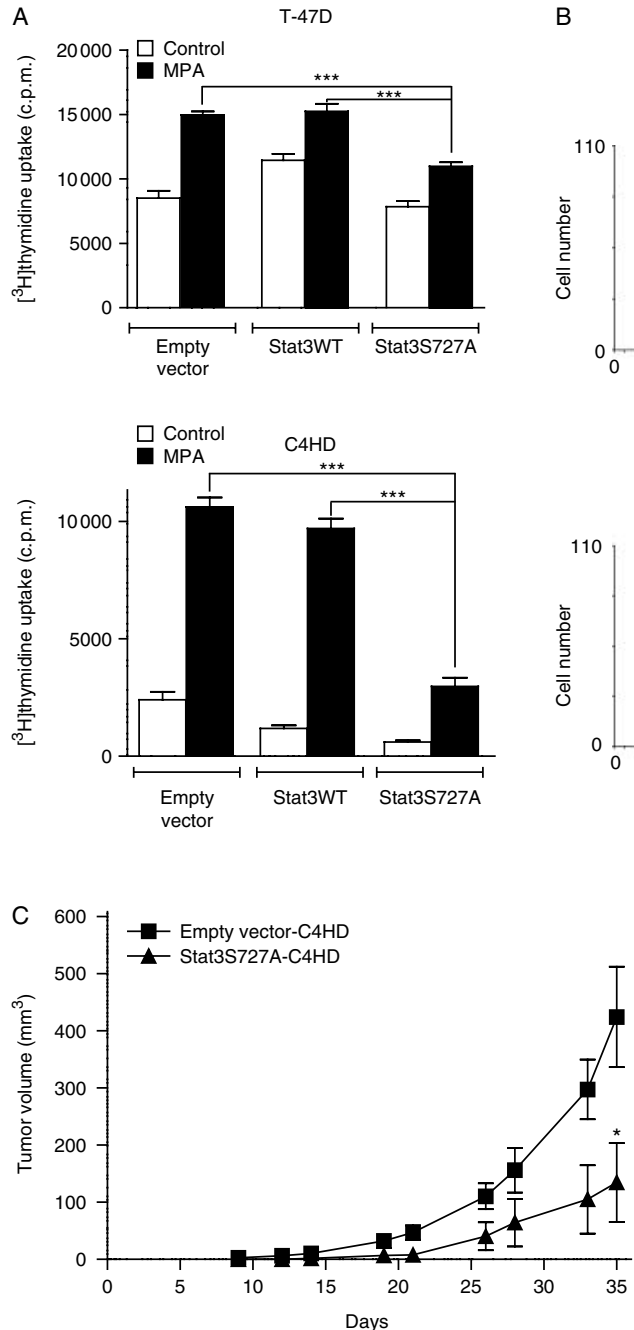
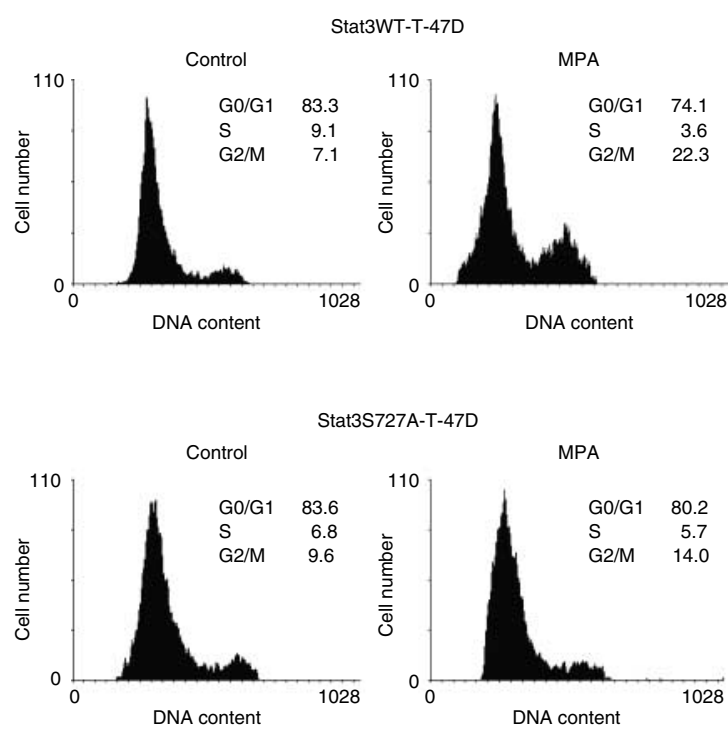

D

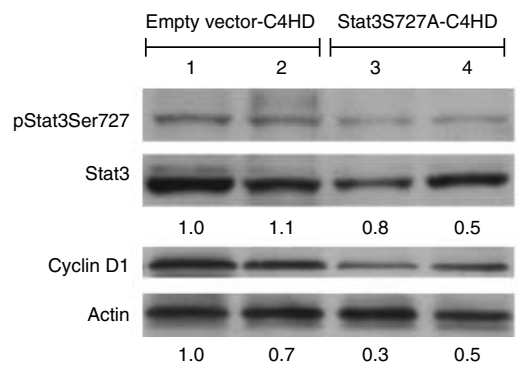

\section{Figure 5}

Serine 727 phosphorylation is required for in vitro and in vivo breast cancer proliferation. (A) T-47D and C4HD were transfected with either the empty vector (pcDNA5/FRT) or Stat3WT or Stat35727A expression vectors and were treated with MPA for 24 or $48 \mathrm{~h}$ respectively. Incorporation of $\left[{ }^{3} \mathrm{H}\right]$ thymidine was used as a measure of DNA synthesis. Data are presented as mean \pm s.D. of octuplicates. Statistical significances are calculated against the MPA-treated empty vector or Stat3WT-transfected cells $(* * * P<0.001)$. The experiments were repeated three times with similar results. (B) T-47D cells were transfected with Stat3WT or Stat35727A expression vectors before MPA stimulation for $24 \mathrm{~h}$ and were then stained with propidium iodide and analyzed for cell cycle distribution by flow cytometry. Data from the experiments shown are representative of those from a total of four experiments. (C) Effect of blockade of Stat3Ser727 phosphorylation on C4HD in vivo growth. C4HD cells $\left(10^{6}\right)$ from each experimental group (empty vector-C4HD or Stat3S727A-C4HD) were inoculated s.c. into mice

experimental group were inoculated s.c. into animals treated with a $40 \mathrm{mg}$ MPA depot in the flank opposite to the cell inoculum, and tumor width and length were measured three times a week for 35 days in order to calculate volume. As shown in Fig. 5C, the expression of treated with MPA. Each point represents the mean volume of five tumors \pm s.D. The experiment was repeated twice with similar results $\left({ }^{*} P<0.05\right)$. (D) Stat3Ser727 phosphorylation and cyclin D1 expression in C4HD tumors. Tumor lysates were analyzed by WB with pStat3S727 or cyclin D1 antibodies. Shown are two representative samples of mice injected with empty vector-C4HD cells (lanes 1 and 2 ) and with Stat3S727A-C4HD cells (lanes 3 and 4). Membranes were then stripped and hybridized with an anti-Stat3 or anti-actin antibodies. In all cases, bands were quantified using Image J, phospho-Stat3 protein band values were normalized to total Stat3 protein bands, and cyclin D1 bands were normalized to actin bands. The first sample of empty vector-C4HD cells was set as 1.0 . There was significant inhibition of cyclin D1 and Stat3Ser727 phosphorylation in mice injected with C4HD-Stat3S727A cells with respect to mice injected with empty vector C4HD cells $(P<0.01)$.

Stat3S727A in C4HD cells strongly inhibited MPA-induced tumor growth. The mean volume and growth rates of tumors that developed from Stat3S727A-C4HD cells were significantly lower than the tumors from the control group (Supplementary Table 1, see section on 
supplementary data given at the end of this article). At the end of the experiment, we prepared tumor extracts and explored levels of Stat3Ser727 phosphorylation and cyclin D1 expression. As shown in Fig. 5D, significantly lower levels of Stat3Ser727 phosphorylation and cyclin D1 were found in tumors developed in mice injected with Stat3S727A-C4HD cells than in tumors of mice injected with empty vector-C4HD cells. The expression of the Stat3S727A-GFP fusion protein was not detected by WB at the end of the experiment (day 35). Histopathological analysis of tumors from Stat3S727A-C4HD cells showed extensive fibrotic areas and also displayed a marked decrease in mitotic figures when compared with tumors from empty vector-C4HD cells (Supplementary Table 1). As a whole, these results further support the direct relevance of Stat3Ser727 phosphorylation in progestininduced in vitro an in vivo breast cancer proliferation.

\section{Ser727 phosphorylation of Stat3 is associated with PR expression in invasive ductal carcinomas}

Because the above-described in vitro and in vivo assays provided evidence that progestins induce Stat3Ser727 phosphorylation, which is essential for up-regulating cyclin D1 expression and cell proliferation, we explored whether Stat3Ser727 phosphorylation correlates with various clinicopathological parameters in patients with invasive ductal carcinomas. TMAs from 48 tumor samples from our cohort, obtained from patients before therapy, were analyzed for nuclear expression of pStat3Ser727 by immunofluorescence using a specific antibody. Expressions of ER and PR were performed by IHC using the corresponding antibodies. Of the 48 tumor samples on the TMAs, 39 tumor cores (82\%) were interpretable for Stat 3 staining. Clinical and pathological characteristics of these specimens are shown in Supplementary Table 2, see section on supplementary data given at the end of this article. Positive nuclear Stat3Ser727 staining was observed in $27(69.2 \%$, Table 1) of these samples (scores 1-3; Fig. 6A). Distribution of Stat 3 nuclear pStat3Ser727 scores is shown in Fig. $6 \mathrm{~B}$ and was similar to the one distribution previously reported for pStat3Tyr705 (Sato et al. 2011). When we examined the possible correlation among various clinicopathological parameters, we found that the nuclear localization of pStat3Ser727 significantly correlated with the presence of PR $(P=0.027$, Table 1$)$. In fact, among the PR-positive tumors, 22 out of 27 (81\%) presented pStat3Ser727 nuclear localization. By contrast, among the PR-negative tumors, only 37\% presented pStat3Ser727 nuclear localization (three out of eight
Table 1 Association between nuclear pStat3Ser727 expression and clinicopathological characteristics in breast cancer.

\begin{tabular}{|c|c|c|c|}
\hline & \multicolumn{2}{|c|}{ Total cohort $(n=39)$} & \multirow[b]{3}{*}{$P$ value $^{a}$} \\
\hline & \multicolumn{2}{|c|}{ pStat3Ser727 (n (\%)) } & \\
\hline & Negative & Positive & \\
\hline Total patients $(n(\%))$ & $12(30.8)$ & $27(69.2)$ & \\
\hline \multicolumn{4}{|l|}{ Tumor size } \\
\hline$\leq 20 \mathrm{~mm}$ & $5(41.7)$ & $14(56.0)$ & 0.321 \\
\hline$>20 \mathrm{~mm}$ & $7(58.3)$ & $11(44.0)$ & \\
\hline Total $(n(\%))$ & $12(32.4)$ & $25(67.6)$ & \\
\hline \multicolumn{4}{|l|}{ Nodal metastasis } \\
\hline Negative & $8(66.7)$ & $14(56.0)$ & 0.401 \\
\hline Positive & $4(33.3)$ & $11(44.0)$ & \\
\hline Total $(n(\%))$ & $12(32.4)$ & $25(67.6)$ & \\
\hline \multicolumn{4}{|l|}{ Distant metastasis } \\
\hline Mo & $11(91.7)$ & $26(100.0)$ & 0.316 \\
\hline M1 & $1(8.3)$ & $0(0)$ & \\
\hline Total $(n(\%))$ & $12(31.6)$ & $26(68.4)$ & \\
\hline \multicolumn{4}{|l|}{ Clinical stages } \\
\hline I & $4(33.3)$ & $11(40.7)$ & 0.472 \\
\hline II+III+IV & $8(66.7)$ & $16(59.3)$ & \\
\hline Total $(n(\%))$ & $12(30.8)$ & $27(69.2)$ & \\
\hline \multicolumn{4}{|l|}{ Tumor grade } \\
\hline $\begin{array}{l}\text { Well to moderately } \\
\text { differentiated }^{\mathrm{b}}\end{array}$ & $5(41.7)$ & $17(70.8)$ & 0.092 \\
\hline Poorly differentiated & $7(58.3)$ & $7(29.2)$ & \\
\hline Total $(n(\%))$ & $12(33.3)$ & $24(66.7)$ & \\
\hline \multicolumn{4}{|l|}{ ER expression } \\
\hline Negative & $3(30.0)$ & $1(4.0)$ & 0.061 \\
\hline Positive & $7(70.0)$ & $24(96.0)$ & \\
\hline Total $(n(\%))$ & $10(28.6)$ & $25(71.4)$ & \\
\hline \multicolumn{4}{|l|}{ PR expression } \\
\hline Negative & $5(50.0)$ & $3(12.0)$ & 0.027 \\
\hline Positive & $5(50.0)$ & $22(88.0)$ & \\
\hline Total $(n(\%))$ & $10(28.6)$ & $25(71.4)$ & \\
\hline
\end{tabular}

$E R$, estrogen receptor; $P R$, progesterone receptor

${ }^{\mathrm{a}}$ Fisher's exact test.

bWell to moderately differentiated: tumor grades 1 and 2, poorly differentiated: tumor grade 3 .

tumors). We observed a trend for nuclear localization of pStat3Ser727 and ER expression, but the difference was not statistically significant $(P=0.061)$.

\section{Discussion}

In this study, we have shown that progestins are able to induce Stat3Ser727 phosphorylation and that the c-Src/p42/p44 MAPK signaling pathway is involved in this phosphorylation event. In addition, we have shown that Ser727 phosphorylation of Stat3 is required to induce cyclin D1 expression and to promote in vivo and in vitro breast cancer cell proliferation. These findings contribute to a better understanding of the participation of nongenomic progestins effect on breast cancer growth,

Published by Bioscientifica Ltd. 

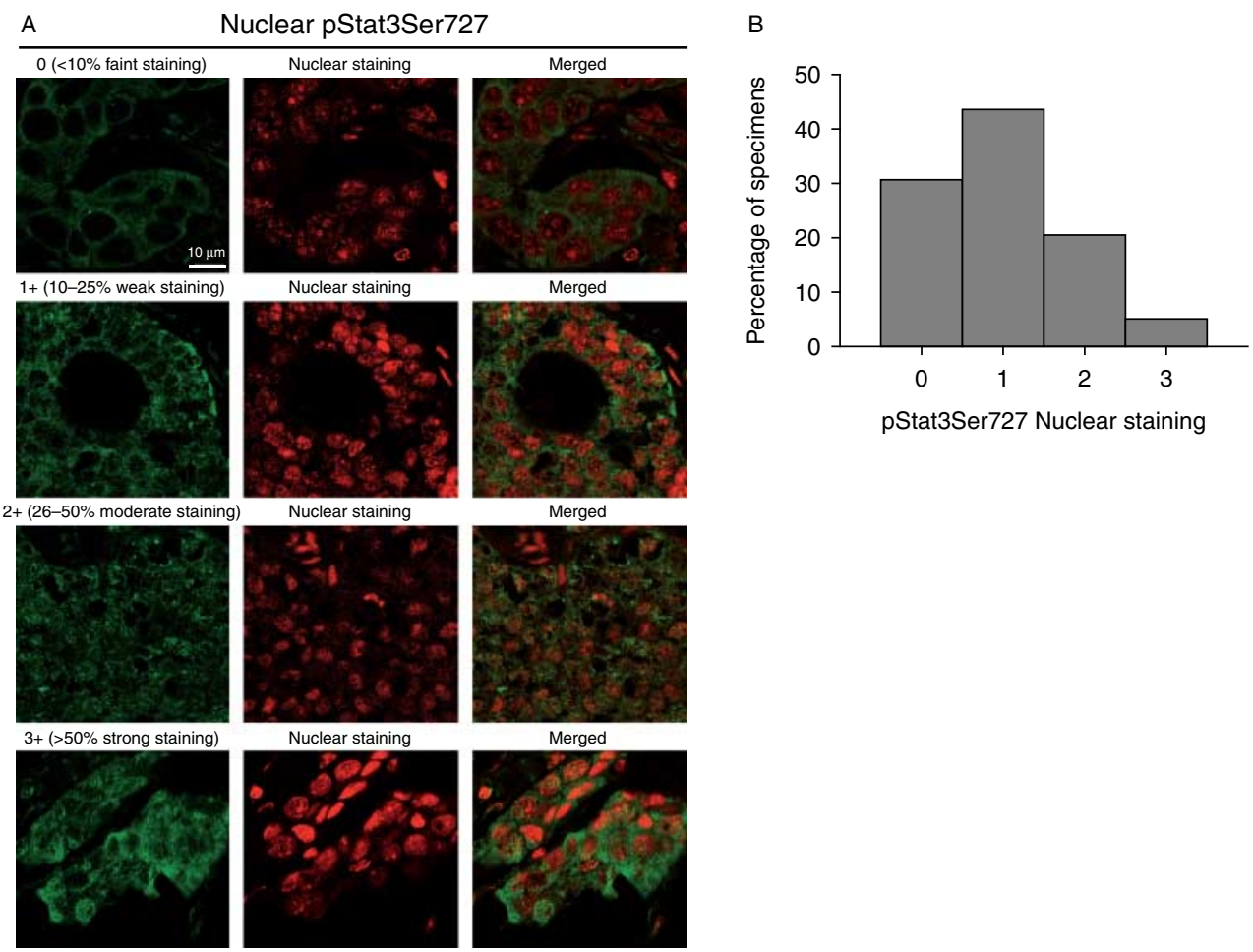

\section{Figure 6}

Cellular localization of pStat3Ser727 in invasive breast carcinomas. (A) Nuclear pStat3Ser727 score. Immunofluorescence staining of breast cancer specimens with anti-pStat3Ser727 antibody (green) and confocal analysis (see Materials and Methods section for antibody specifications).
Nuclei were stained with propidium iodide (red). Merged images show nuclear localization of pStat3Ser727 in tumor samples. (B) Distribution of nuclear pStat3Ser727 immunofluorescence staining scores in invasive breast carcinomas (0-3). showing that phosphorylation of Stat3 in serine 727 is an essential event.

A wide variety of kinases participating in Ser727 phosphorylation of Stat 3 have been described in diverse cell types and stimuli such as MAPK, including p42/p44 MAPK, c-Jun kinases (JNK), p38 MAPK, PKCe, and mTOR kinases (Decker \& Kovarik 2000). Recently, PKC\& oncogenic activity was disclosed to proceed through the activation of Raf-1, MEK-1, and p42/p44 MAPK to phosphorylate Stat3 at Ser727 residue. The event of Stat3Ser727 phosphorylation was recognized to be essential for PKC $\mathrm{P}$-induced invasion in various human cancer (Aziz et al. 2010). With respect to the rapid signaling of PR, Auricchio and coworkers described a nongenomic effect of progestins that accounts for the activation of the c-Src/p21ras/p42/p44 MAPK signaling pathway in human breast cancer cell line T-47D (Migliaccio et al. 1998, Ballare et al. 2003). Moreover, our own previous findings demonstrate that progestins induce Stat3Tyr705 phosphorylation through the activation of the c-Src/Jak signaling cascade (Proietti et al. 2005). These effects of progestins on cell signaling in the absence of transcription are dependent on classical PR. Indeed, human PR has, in the amino terminal domain, a polyproline motif (amino acids 421-428) that mediates direct interaction of PR with the SH3 domain of the nonreceptor tyrosine kinase c-Src and activates this kinase by an SH3 domain displacement mechanism (Boonyaratanakornkit et al. 2001). Evidence confirms that c-Src activation is mediated by PR outside the nucleus, supporting the fact that only PR-B can stimulate c-Src and not PR-A, which is mostly nuclear (Boonyaratanakornkit et al. 2007). In our reconstitution experiments in human PR null T-47D-Y breast cancer cells with the PR-BmPro, that lacks the polyproline motifs necessary for PR activation of c-Src, MPA treatment was not able to phosphorylate Stat3 at Ser727 residue. Interestingly, we found that MPA induces $\mathrm{p} 42 / \mathrm{p} 44$ MAPK activation via c-Src in C4HD cells. Although mouse PR lacks the polyproline motif, we have already demonstrated that MPA induces c-Src activation and p42/p44 MAPK in C4HD murine cells (Proietti et al. 2005, Carnevale et al. 2007). Moreover, we recently

Published by Bioscientifica Ltd. 
described the importance of phosphorylation on Ser 294 in human and mouse PR regulation of c-Src activity in response to heregulin (Proietti et al. 2009). Taking into account that MPA induces phosphorylation of PR on Ser 294 residue (Shen et al. 2001), this activated receptor could in turn also induce c-Src activation.

The evidence provided here supports a direct link between c-Src/p42/p44 MAPK and Stat3Ser727 phosphorylation. First, addition of the p42/p44 MAPK pathway inhibitor, U0126, resulted in abolishment of MPA capacity to phosphorylate Stat3Ser727. Secondly, inhibition of c-Src activity by pharmacological inhibitors (PP2 and dasatinib) prevented MPA-induced p42/p44 MAPK activation and Stat3Ser727 phosphorylation. Finally, the in vitro phosphorylation assay indicated that MPAactivated p42/p44 MAPK can phosphorylate Stat3 at Ser727 residue. Together, all these data strongly suggest that MPA triggers a signaling cascade inducing the sequential activation of c-Src, p42/p44 MAPK that leads to Stat3Ser727 phosphorylation both in human and in mouse breast cancer cells. There are several reports supporting the fact that the biological involvement of Stat3Ser727 phosphorylation is to achieve the full transcriptional activation of Stat3 (Wen et al. 1995, Decker \& Kovarik 2000). Indeed, Shen et al. (2004) observed a marked reduction in Stat3 transcriptional activation in vivo when expressing the Stat35727A mutant. As described earlier, the dominant negative mechanism of Stat3S727A relies on the ability to form homo- or heterodimers with the endogenous WT protein, resulting in poor transcriptional activation (Zhang et al. 1996, Bromberg et al. 1998). On the other hand, Ser727phosphorylated Stat3 has also been suggested to mediate activation of transcription without detectable Tyr705 phosphorylation, as recently reported in chronic lymphocytic leukemia (Hazan-Halevy et al. 2010). Collectively, the available data indicate that the effect of Stat3Ser727 phosphorylation probably depends on the type of extracellular stimulus, cell type, and the activation status of the cell studied. Our results indicate that the presence of the Stat3S727A mutant abolished the transcriptional activity of the $\mathrm{m} 67$ reporter and of cyclin D1 promoter. Moreover, our ChIP results on the cyclin D1 GAS site confirmed that Stat 3 was not recruited to the promoter in the presence of Stat3S727A.

It is well acknowledged that cyclin D1 is a requirement for breast carcinogenesis (Yu et al. 2001). Here, we showed that progestin induction of cyclin D1 gene expression is dependent on the c-Src/p42/p44 MAPK/pStat3Ser727 signaling cascade. Moreover, in our present study, we found that this phosphorylation event is essential for progestin-induced breast cancer proliferation. We found that the presence of phosphorylated Stat3 at Ser727 is a requisite for progestin stimulation of in vitro and in vivo breast cancer growth. These findings support new avenues for therapeutic approaches targeting p42/p44 MAPK signaling, like the MEK inhibitor AZD6244 that is now in phase II trials for several malignancies ( $\mathrm{O}^{\prime} \mathrm{Neil}$ et al. 2011, Patel \& Kim 2012).

Interestingly, our clinical data show for the first time that there is an association between increased levels of pStat3Ser727 and PR expression in invasive ductal breast carcinomas. Indeed, we observed that $81 \%$ of PR-positive tumors also express nuclear pStat3Ser727, which provides support to accumulating evidence showing Stat3 activation in breast tumor samples (Dolled-Filhart et al. 2003, Sato et al. 2011). Moreover, our data suggest that phosphorylation in Ser727 residue may be attributable to the presence of PR and consequently to progestin action in breast cancer patients.

In conclusion, our present findings reveal that acting through a nongenomic signaling cascade, progestin is able to phosphorylate Stat3 in Ser727 residue leading to in vivo cyclin D1 upregulation and breast cancer growth. Thus, our results presented here encourage further exploration of the potential therapeutic value of targeting Stat3 through inhibition of upstream p42/p44 MAPK signaling in PR-positive breast tumors.

\section{Supplementary data}

This is linked to the online version of the paper at http://dx.doi.org/10.1677/ ERC-12-0194.

\section{Declaration of interest}

The authors declare that there is no conflict of interest that could be perceived as prejudicing the impartiality of the research reported.

\section{Funding}

This work was supported in part by the Susan G Komen for the Cure investigator-initiated research grant (KG090250 to P V Elizalde), The National Agency of Scientific Promotion of Argentina (PICT 2010 \#0122), The Argentina National Council of Scientific Research (PIP 737), and Oncomed-Reno CONICET (1819/03).

\section{Acknowledgements}

The authors wish to thank Dr Alfredo A Molinolo (NIH, Bethesda, MD, USA) for his constant help and support. The authors thank Dr B Elsner for collecting biopsies and Dr M Russo for collecting clinicopathological data.

Published by Bioscientifica Ltd. 
References

Aziz MH, Hafeez BB, Sand JM, Pierce DB, Aziz SW, Dreckschmidt NE \& Verma AK 2010 Protein kinase Cvarepsilon mediates Stat3Ser727 phosphorylation, Stat3-regulated gene expression, and cell invasion in various human cancer cell lines through integration with MAPK cascade (RAF-1, MEK1/2, and ERK1/2). Oncogene 29 3100-3109. (doi:10.1038/onc.2010.63)

Balana ME, Lupu R, Labriola L, Charreau EH \& Elizalde PV 1999 Interactions between progestins and heregulin (HRG) signaling pathways: HRG acts as mediator of progestins proliferative effects in mouse mammary adenocarcinomas. Oncogene 18 6370-6379. (doi:10.1038/sj.onc.1203028)

Ballare C, Uhrig M, Bechtold T, Sancho E, Di Domenico M, Migliaccio A, Auricchio F \& Beato M 2003 Two domains of the progesterone receptor interact with the estrogen receptor and are required for progesterone activation of the c-Src/Erk pathway in mammalian cells. Molecular and Cellular Biology 23 1994-2008. (doi:10.1128/MCB.23.6.1994-2008. 2003)

Beguelin W, Diaz Flaque MC, Proietti CJ, Cayrol F, Rivas MA, Tkach M, Rosemblit C, Tocci JM, Charreau EH, Schillaci R et al. 2010 Progesterone receptor induces ErbB-2 nuclear translocation to promote breast cancer growth via a novel transcriptional effect: ErbB-2 function as a coactivator of Stat3. Molecular and Cellular Biology 30 5456-5472. (doi:10.1128/MCB.00012-10)

Beral V 2003 Breast cancer and hormone-replacement therapy in the Million Women Study. Lancet 362 419-427. (doi:10.1016/S01406736(03)14596-5)

Boonyaratanakornkit V, Scott MP, Ribon V, Sherman L, Anderson SM, Maller JL, Miller WT \& Edwards DP 2001 Progesterone receptor contains a proline-rich motif that directly interacts with SH3 domains and activates c-Src family tyrosine kinases. Molecular Cell 8 269-280. (doi:10.1016/S1097-2765(01)00304-5)

Boonyaratanakornkit V, McGowan E, Sherman L, Mancini MA, Cheskis BJ \& Edwards DP 2007 The role of extranuclear signaling actions of progesterone receptor in mediating progesterone regulation of gene expression and the cell cycle. Molecular Endocrinology 21 359-375. (doi:10.1210/me.2006-0337)

Bowman T, Garcia R, Turkson J \& Jove R 2000 STATs in oncogenesis. Oncogene 19 2474-2488. (doi:10.1038/sj.onc.1203527)

Bromberg JF, Horvath CM, Besser D, Lathem WW \& Darnell JE, Jr 1998 Stat 3 activation is required for cellular transformation by $\mathrm{v}$-src. Molecular and Cellular Biology 18 2553-2558.

Bromberg JF, Wrzeszczynska MH, Devgan G, Zhao Y, Pestell RG, Albanese C \& Darnell JE, Jr 1999 Stat3 as an oncogene. Cell 98 295-303. (doi:10.1016/S0092-8674(00)81959-5)

Carnevale RP, Proietti CJ, Salatino M, Urtreger A, Peluffo G, Edwards DP, Boonyaratanakornkit V, Charreau EH, Bal de Kier JE, Schillaci R et al. 2007 Progestin effects on breast cancer cell proliferation, proteases activation, and in vivo development of metastatic phenotype all depend on progesterone receptor capacity to activate cytoplasmic signaling pathways. Molecular Endocrinology 21 1335-1358. (doi:10.1210/ me.2006-0304)

Darnell JE, Jr, Kerr IM \& Stark GR 1994 Jak-STAT pathways and transcriptional activation in response to IFNs and other extracellular signaling proteins. Science 264 1415-1421. (doi:10.1126/science. 8197455)

Decker T \& Kovarik P 2000 Serine phosphorylation of STATs. Oncogene 19 2628-2637. (doi:10.1038/sj.onc.1203481)

De Miguel F, Lee SO, Onate SA \& Gao AC 2003 Stat3 enhances transactivation of steroid hormone receptors. Nuclear Receptor 13. (doi:10.1186/1478-1336-1-3)

Dolled-Filhart M, Camp RL, Kowalski DP, Smith BL \& Rimm DL 2003 Tissue microarray analysis of signal transducers and activators of transcription 3 (Stat3) and phospho-Stat3 (Tyr705) in node-negative breast cancer

http://erc.endocrinology-journals.org DOI: 10.1530/ERC-12-0194
(C) 2013 Society for Endocrinology Printed in Great Britain shows nuclear localization is associated with a better prognosis. Clinical Cancer Research 9 594-600.

Gonzalez FA, Raden DL \& Davis RJ 1991 Identification of substrate recognition determinants for human ERK1 and ERK2 protein kinases. Journal of Biological Chemistry 66 22159-22163.

Gritsko T, Williams A, Turkson J, Kaneko S, Bowman T, Huang M, Nam S, Eweis I, Diaz N, Sullivan D et al. 2006 Persistent activation of Stat3 signaling induces survivin gene expression and confers resistance to apoptosis in human breast cancer cells. Clinical Cancer Research 12 11-19. (doi:10.1158/1078-0432.CCR-04-1752)

In Guide for the Care and Use of Laboratory Animals 1996. Institute of Laboratory Animal Resources, Commission on Life Sciences National Research Council. Washington, DC: National Academy Press.

Hazan-Halevy I, Harris D, Liu Z, Liu J, Li P, Chen X, Shanker S, Ferrajoli A, Keating MJ \& Estrov Z 2010 STAT3 is constitutively phosphorylated on serine 727 residues, binds DNA, and activates transcription in CLL cells. Blood 115 2852-2863. (doi:10.1182/blood-2009-10-230060)

Heinrich PC, Behrmann I, Muller-Newen G, Schaper F \& Graeve L 1998 Interleukin-6-type cytokine signalling through the gp130/Jak/STAT pathway. Biochemical Journal 334 (Pt 2) 297-314.

Lee H, Herrmann A, Deng JH, Kujawski M, Niu G, Li Z, Forman S, Jove R, Pardoll DM \& Yu H 2009 Persistently activated Stat3 maintains constitutive NF- $\kappa$ B activity in tumors. Cancer Cell 15 283-293. (doi:10.1016/j.ccr.2009.02.015)

Leslie K, Lang C, Devgan G, Azare J, Berishaj M, Gerald W, Kim YB, Paz K, Darnell JE, Albanese C et al. 2006 Cyclin D1 is transcriptionally regulated by and required for transformation by activated signal transducer and activator of transcription 3. Cancer Research 66 2544-2552. (doi:10.1158/0008-5472.CAN-05-2203)

Lanari C, Lamb CA, Fabris VT, Helguero LA, Soldati R, Bottino MC, Giulianelli S, Cerliani JP, Wargon V \& Molinolo A 2009 The MPA mouse breast cancer model: evidence for a role of progesterone receptors in breast cancer. Endocrine-Related Cancer 16 333-350. (doi:10.1677/ERC08-0244)

Migliaccio A, Piccolo D, Castoria G, Di Domenico M, Bilancio A, Lombardi M, Gong W, Beato M \& Auricchio F 1998 Activation of the Src/p21ras/Erk pathway by progesterone receptor via cross-talk with estrogen receptor. EMBO Journal 17 2008-2018. (doi:10.1093/emboj/ 17.7.2008)

Olayioye MA, Beuvink I, Horsch K, Daly JM \& Hynes NE 1999 ErbB receptor-induced activation of Stat transcription factors is mediated by Src tyrosine kinases. Journal of Biological Chemistry 274 17209-17218. (doi:10.1074/jbc.274.24.17209)

O'Neil BH, Goff LW, Kauh JS, Strosberg JR, Bekaii-Saab TS, Lee RM, Kazi A, Moore DT, Learoyd M, Lush RM et al. 2011 Phase II study of the mitogen-activated protein kinase $1 / 2$ inhibitor selumetinib in patients with advanced hepatocellular carcinoma. Journal of Clinical Oncology 29 2350-2356. (doi:10.1200/JCO.2010.33.9432)

Page DL, Ellis IO \& Elston CW 1995 Histologic grading of breast cancer. Let's do it. American Journal of Clinical Pathology 103 123-124.

Patel SP \& Kim KB 2012 Selumetinib (AZD6244; ARRY-142886) in the treatment of metastatic melanoma. Expert Opinion on Investigational Drugs 21 531-539. (doi:10.1517/13543784.2012.665871)

Pietra LD, Bressan A, Pezzotti AR \& Serlupi-Crescenzi O 1998 Highly conserved amino-acid sequence between murine STAT3 and a revised human STAT3 sequence. Gene 213 119-124. (doi:10.1016/S03781119(98)00185-1)

Proietti C, Salatino M, Rosemblit C, Carnevale R, Pecci A, Kornblihtt AR, Molinolo AA, Frahm I, Charreau EH, Schillaci R et al. 2005 Progestins induce transcriptional activation of signal transducer and activator of transcription 3 (Stat3) via a Jak- and Src-dependent mechanism in breast cancer cells. Molecular and Cellular Biology 25 4826-4840. (doi:10.1128/MCB.25.12.4826-4840.2005)

Proietti CJ, Rosemblit C, Beguelin W, Rivas MA, Diaz Flaque MC, Charreau EH, Schillaci R \& Elizalde PV 2009 Activation of Stat3 by heregulin/ErbB-2 through the co-option of progesterone receptor signaling drives breast 
cancer growth. Molecular and Cellular Biology 29 1249-1265. (doi:10.1128/ MCB.00853-08)

Real PJ, Sierra A, De Juan A, Segovia JC, Lopez-Vega JM \& Fernandez-Luna JL 2002 Resistance to chemotherapy via Stat3-dependent overexpression of Bcl-2 in metastatic breast cancer cells. Oncogene 21 7611-7618. (doi:10.1038/sj.onc.1206004)

Richer JK, Lange CA, Manning NG, Owen G, Powell R \& Horwitz KB 1998 Convergence of progesterone with growth factor and cytokine signaling in breast cancer. Progesterone receptors regulate signal transducers and activators of transcription expression and activity. Journal of Biological Chemistry 273 31317-31326. (doi:10.1074/jbc.273. 47.31317)

Rivas MA, Carnevale RP, Proietti CJ, Rosemblit C, Beguelin W, Salatino M, Charreau EH, Frahm I, Sapia S, Brouckaert P et al. 2008 TNF $\alpha$ acting on TNFR1 promotes breast cancer growth via p42/P44 MAPK, JNK, Akt and NF-кB-dependent pathways. Experimental Cell Research 314 509-529. (doi:10.1016/j.yexcr.2007.10.005)

Rivas MA, Tkach M, Beguelin W, Proietti CJ, Rosemblit C, Charreau EH, Elizalde PV \& Schillaci R 2010 Transactivation of ErbB-2 induced by tumor necrosis factor $\alpha$ promotes NF- $\kappa \mathrm{B}$ activation and breast cancer cell proliferation. Breast Cancer Research and Treatment 122 111-124. (doi:10.1007/s10549-009-0546-3)

Sartorius CA, Groshong SD, Miller LA, Powell RL, Tung L, Takimoto GS \& Horwitz KB 1994 New T47D breast cancer cell lines for the independent study of progesterone B- and A-receptors: only antiprogestin-occupied B-receptors are switched to transcriptional agonists by cAMP. Cancer Research 54 3868-3877.

Sasse J, Hemmann U, Schwartz C, Schniertshauer U, Heesel B, Landgraf C, Schneider-Mergener J, Heinrich PC \& Horn F 1997 Mutational analysis of acute-phase response factor/Stat 3 activation and dimerization. Molecular and Cellular Biology 17 4677-4686.

Sato T, Neilson LM, Peck AR, Liu C, Tran TH, Witkiewicz A, Hyslop T, Nevalainen MT, Sauter G \& Rui H 2011 Signal transducer and activator of transcription-3 and breast cancer prognosis. American Journal of Cancer Research 1 347-355.

Schillaci R, Salatino M, Cassataro J, Proietti CJ, Giambartolomei GH, Rivas MA, Carnevale RP, Charreau EH \& Elizalde PV 2006 Immunization with murine breast cancer cells treated with antisense oligodeoxynucleotides to type I insulin-like growth factor receptor induced an antitumoral effect mediated by a CD8 + response involving Fas/Fas ligand cytotoxic pathway. Journal of Immunology 176 3426-3437.

Schillaci R, Guzman P, Cayrol F, Beguelin W, Diaz Flaque MC, Proietti CJ, Pineda V, Palazzi J, Frahm I, Charreau EH et al. 2012 Clinical relevance of ErbB-2/HER2 nuclear expression in breast cancer. BMC Cancer 1274. (doi:10.1186/1471-2407-12-74)

Shen T, Horwitz KB \& Lange CA 2001 Transcriptional hyperactivity of human progesterone receptors is coupled to their ligand-dependent down-regulation by mitogen-activated protein kinase-dependent phosphorylation of serine 294. Molecular and Cellular Biology 21 6122-6131. (doi:10.1128/MCB.21.18.6122-6131.2001)

Shen Y, Schlessinger K, Zhu X, Meffre E, Quimby F, Levy DE \& Darnell JE, Jr 2004 Essential role of STAT3 in postnatal survival and growth revealed by mice lacking STAT3 serine 727 phosphorylation. Molecular and Cellular Biology 24 407-419. (doi:10.1128/MCB.24.1.407-419.2004)

Silvennoinen O, Schindler C, Schlessinger J \& Levy DE 1993 Rasindependent growth factor signaling by transcription factor tyrosine phosphorylation. Science 261 1736-1739. (doi:10.1126/science. 8378775)

Singletary SE, Allred C, Ashley P, Bassett LW, Berry D, Bland KI, Borgen PI, Clark G, Edge SB, Hayes DF et al. 2002 Revision of the American Joint Committee on Cancer staging system for breast cancer. Journal of Clinical Oncology 20 3628-3636. (doi:10.1200/JCO.2002.02.026)

Skildum A, Faivre E \& Lange CA 2005 Progesterone receptors induce cell cycle progression via activation of mitogen-activated protein kinases. Molecular Endocrinology 19 327-339. (doi:10.1210/me.2004-0306)

Sud N, Kumar S, Wedgwood S \& Black SM 2009 Modulation of PKC $\delta$ signaling alters the shear stress-mediated increases in endothelial nitric oxide synthase transcription: role of STAT3. American Journal of Physiology. Lung Cellular and Molecular Physiology 296 L519-L526. (doi:10.1152/ajplung.90534.2008)

Tsai MJ \& O'Malley BW 1994 Molecular mechanisms of action of steroid/thyroid receptor superfamily members. Annual Review of Biochemistry 63 451-486. (doi:10.1146/annurev.bi.63.070194.002315)

Turner NA, Das A, Warburton P, O'Regan DJ, Ball SG \& Porter KE 2009 Interleukin- $1 \alpha$ stimulates proinflammatory cytokine expression in human cardiac myofibroblasts. American Journal of Physiology. Heart and Circulatory Physiology 297 H1117-H1127. (doi:10.1152/ajpheart. 00372.2009)

Wen Z, Zhong Z \& Darnell JE, Jr 1995 Maximal activation of transcription by Stat 1 and Stat 3 requires both tyrosine and serine phosphorylation. Cell 82 241-250. (doi:10.1016/0092-8674(95)90311-9)

Yu H \& Jove R 2004 The STATs of cancer - new molecular targets come of age. Nature Reviews. Cancer 4 97-105. (doi:10.1038/nrc1275)

Yu Q, Geng Y \& Sicinski P 2001 Specific protection against breast cancers by cyclin D1 ablation. Nature 411 1017-1021. (doi:10.1038/35082500)

Zhang Q, Nowak I, Vonderheid EC, Rook AH, Kadin ME, Nowell PC, Shaw LM \& Wasik MA 1996 Activation of Jak/STAT proteins involved in signal transduction pathway mediated by receptor for interleukin 2 in malignant $\mathrm{T}$ lymphocytes derived from cutaneous anaplastic large T-cell lymphoma and Sezary syndrome. PNAS 93 9148-9153. (doi:10.1073/pnas.93.17.9148)

Zhang Y, Turkson J, Carter-Su C, Smithgall T, Levitzki A, Kraker A, Krolewski JJ, Medveczky P \& Jove R 2000 Activation of Stat3 in v-Srctransformed fibroblasts requires cooperation of Jak1 kinase activity. Journal of Biological Chemistry 275 24935-24944. (doi:10.1074/ jbc.M002383200)

Received in final form 10 December 2012

Accepted 14 January 2013

Made available online as an Accepted Preprint

17 January 2013 http://erc.endocrinology-journals.org

DOI: 10.1530/ERC-12-0194
(C) 2013 Society for Endocrinology Printed in Great Britain
Published by Bioscientifica Ltd. 